\title{
Are Symptom-Based Diagnostic Criteria for Irritable Bowel Syndrome Useful in Clinical Practice?
}

\author{
Maura Corsetti Jan Tack \\ Department of Internal Medicine, Division of Gastroenterology, \\ University Hospital Gasthuisberg, University of Leuven, Leuven, Belgium
}

Symptoms consistent with irritable bowel syndrome (IBS) are reported by $10-20 \%$ of the Western population, but only a subgroup of people with IBS request medical attention and the majority of them are managed in primary care [1]. Considering that there is no biological marker for IBS, symptom-based diagnostic criteria have been developed in order to achieve a positive diagnosis of IBS and to ensure the homogeneity of patient populations in clinical research settings [1]. Kruis et al. [2] used a combination of clinical criteria and simple laboratory tests to develop a scoring system that differentiated IBS from organic disease in tertiary care patients. However, the scoring system and the addition of laboratory tests precluded a wide application, and pure symptom-based criteria were developed based on expert opinion and the Kruis scoring system. The criteria of Manning et al. [3] define IBS according to the presence of pain associated with altered bowel habit or defecation; the Rome I criteria added that these symptoms have to be continuous or recurrent for at least 3 months [4], and the Rome II revision added that symptoms have to have been present in the last year [5].

The sensitivity and specificity of these criteria in diagnosing IBS have been evaluated in a study on tertiary care patients [6]. This study has demonstrated a good sensitivity of the Manning criteria and a good specificity of the Rome I criteria. More recent articles have observed that the Rome II criteria are less sensitive compared to the Manning and Rome I criteria [7-9], but only a few studies have addressed the utility and applicability of these criteria in clinical practice $[10,11]$.

In this issue of Digestion, by selecting 68 general practitioners (GPs), 48 hospital gastroenterologists and 100 patients attending an outpatient clinic with a diagnosis of IBS made by experienced gastroenterologist, Lea et al. [12] have investigated the clinical utility of the Manning, Rome I and Rome II criteria. They report that only $20 \%$ of GPs know and $4 \%$ use these criteria, whereas $96 \%$ of consultants know and $70 \%$ use these criteria. The use of the Manning and Rome I criteria exclude from IBS diagnosis only 6 and $12 \%$, respectively, of patients diagnosed in clinical practice. The Rome II criteria exclude 25 and $16 \%$, respectively, of the patients with IBS according to the Manning and Rome I criteria.

These results confirm the findings of previous studies that addressed the diagnosis of IBS in clinical practice $[10,11]$. Gladman and Gorard [10] selected 137 GPs and 167 consultants and reported that 21 and $12 \%$ of GPs and 81 and $83 \%$ of consultants had heard of the Manning and Rome criteria, respectively, but only 11 and 3\% of GPs and 40 and $60 \%$ of consultants had used these criteria. Thompson et al. [11] enrolled 36 GPs and reported that

\begin{tabular}{ll}
\hline KARGER & ( ) 2004 S. Karger AG, Basel \\
0012-2823/04/0704-0207\$21.00/0 \\
$\begin{array}{l}\text { Fax +4161306 1234 } \\
\begin{array}{l}\text { E-Mail karger@karger.ch } \\
\text { www.karger.com }\end{array}\end{array}$ & $\begin{array}{l}\text { Accessible online at: } \\
\text { www.karger.com/dig }\end{array}$
\end{tabular}

\begin{tabular}{l}
\hline Jan Tack, MD, PhD \\
Department of Internal Medicine, Division of Gastroenterology \\
University Hospital Gasthuisberg, Herestraat 49 \\
BE-3000 Leuven (Belgium) \\
Tel. +32 16 3442 25, Fax +32 163444 19, E-Mail jan.tack@med.kuleuven.ac.be
\end{tabular} 
$82 \%$ of the patients diagnosed as having IBS by GPs also met the Manning and Rome I criteria. Moreover the present study extends recent primary care data from epidemiological surveys [7-9] observing that the new Rome II criteria exclude about $20-60 \%$ of patients with IBS diagnosed according to the Manning and Rome I criteria.

These data show that symptom-based diagnostic criteria are not well known and rarely used in primary care, but doctors correctly attributed IBS diagnosis to patients who have IBS according to the Manning and Rome I criteria. On the contrary, the Rome II criteria appear to be too restrictive as they exclude a great proportion of clinically diagnosed patients. As suggested by Lea et al. [12], in the absence of a specific diagnosis these patients could be designated to undergo a number of additional diagnostic tests and treatments that are probably not useful and might increase the costs for the health care system. The reason of the lack of concordance between clinical and Rome IIbased diagnosis seems to reside in the too stringent criteria of duration and the characteristics of pain-related symptoms [9, 12]. A recent article suggests that the Rome II criteria are mainly useful to identify patients with active IBS in clinical research settings [7]. However, as data from research have to be applied to everyday clinical patients, diagnoses in research and reality must be comparable. Thus previous and present studies suggest the necessity of revising the symptom-based criteria for diagnosing IBS in a clinical setting.

As the majority of IBS patients are primarily treated by GPs, these criteria should be adapted to the normal use of GPs in their practice instead of proposing the adaptation of GPs and consultants to the use of symptom-based diagnostic criteria. Some articles have demonstrated that in the process of IBS diagnosis GPs consider useful the pres- ence of a long history of disturbances, of unexplained and multiple symptoms, the absence of symptoms during the night, the age of patients, and the presence of a relation between psychological distress and symptoms $[11,14$, 15]. In other words, the GPs consider the absence of alarm features and the presence of signs referable to multiple organs as useful diagnostically. It should be noted that recent studies have demonstrated that the addition of these clinical aspects (the absence of alarm symptoms) increases the positive predictive value of the Manning or Rome I [6] as well as the Rome II criteria [16] in tertiary care centers.

In this process it is also necessary to define the characteristics of patients in different care settings. Some authors have indeed suggested that patients in primary care are different from those in tertiary care $[11,13,17]$. In these studies the former have a lower number and severity of symptoms, have no history of treatment failure, attribute their symptoms to stress, and have less non-gastrointestinal complaints compared to the latter. A better understanding of the symptom characteristics of IBS patients in different contexts would help to develop criteria applicable to every context.

In conclusion, the results of the present study stress the necessity to revise symptom-based diagnostic criteria for IBS to allow a diagnosis of IBS in every clinical setting as well as to ascertain the homogeneity of the study populations for clinical research. Such a revision should enable a better extension of clinical research to primary care and may also help to converge the approach of physicians at different levels of care to IBS patients. It has been shown that patients in primary care expect diagnostic confidence and reassurance from their GPs [18, 19], and these aspects should benefit from reliable, well-known and easyto-use diagnostic criteria.

\section{References}

1 Drossman DA: The Rome criteria process: Diagnosis and legitimization of irritable bowel syndrome. Am J Gastroenterol 1999;94:28032807.

$>2$ Kruis W, Thieme C, Weinzierl M, Schussler P, Holl J, Paulus W: A diagnostic score for the irritable bowel syndrome. Its value in the exclusion of organic disease. Gastroenterology 1984; 87:1-7.

$\checkmark 3$ Manning AP, Thompson WG, Heaton KW, Morris AF: Towards positive diagnosis of the irritable bowel. Br Med J 1978;ii:653-654.
4 Drossman DA, Thompson WG, Talleny NJ, et al: Identification of subgroups of functional bowel disorders. Gastroenterol Int 1990;3: 159-172.

5 Thompson WG, Longstreth GF, Drossman DA, Heaton KW, Irvine EJ, Muller-Lissner SA: Functional bowel disorders and functional abdominal pain. Gut 1999;45(suppl 2):II43II47.

6 Vanner SJ, Depew WT, Paterson WG, et al: Predictive value of the Rome criteria for diagnosing the irritable bowel syndrome. Am J Gastroenterol 1999;94:2912-2917.
7 Chey WD, Olden K, Carter E, Boyle J, Drossman D, Chang L: Utility of the Rome I and Rome II criteria for irritable bowel syndrome in US women. Am J Gastroenterol 2002;97: 2803-2811.

8 Mearin F, Roset M, Badia X, Balboa A, Baròe, Ponce J, Diaz-Rubio M, Caldwell E, Cucala M, Fueyo A, Talley N: Splitting irritable bowel syndrome: From original Rome to Rome II criteria. Am J Gastroenterol 2003;99:122-130. 
$\checkmark 9$ Boyce PM, Koloski NA, Talley NJ: Irritable bowel syndrome according to varying diagnostic criteria: Are the new Rome II criteria unnecessarily restrictive for research and practice? Am J Gastroenterol 2000;95:3176-3183.

10 Gladman LM, Gorard DA: General practitioner and hospital specialist attitudes to functional gastrointestinal disorders. Aliment Pharmacol Ther 2003; 17:651-654.

11 Thompson WG, Heaton KW, Smyth GT, Smyth C: Irritable bowel syndrome in general practice: Prevalence, characteristics, and referral. Gut 2000;46:78-82.

12 Lea R, Hopkins V, Hastleton J, Houghton LA Whorwell PJ: Diagnostic criteria for irritable bowel syndrome: Utility and applicability in clinical practice. Digestion 2004;70:210-213.
13 Longstreth GF, Hawkey CJ, Mayer EA, Jones RH, Naesdal J, Wilson IK, Peacock RA, Wiklund IK: Characteristics of patients with irritable bowel syndrome recruited for three sources: Implications for clinical trials. Aliment Pharmacol Ther 2001;15:959-964.

4 Mouzas IA, Fragkiadakis N, Moschandreas J, Karachristos A, Skordilis P, Kouroumalis E, Manousos O: Validation and results of a questionnaire for functional bowel disease in outpatients. BMC Public Health 2002;2:1-8.

15 Vandvik PO, Aabakken L, Farup PG: Diagnosing irritable bowel syndrome: Poor agreement between general practitioners and Rome I criteria. Scand J Gastroenterol 2004;39:448-453.

16 Hammer J, Eslick GD, Howell SC, Altiparmak E, Talley NJ: Diagnostic yield of alarm features in irritable bowel syndrome and functional dyspepsia. Gut 2004;53:666-672.
17 van der Horst HE, Dulmen AM, Schellevis FG, van Eijk JThM, Fennis JFM, Bleijenberg G: Do patients with irritable bowel syndrome in primary care really differ from outpatients with irritable bowel syndrome? Gut 1997;41:669_ 674.

8 Bijkerk CJ, de Wit NJ, Stalman WA, Knottnerus JA, Hoes AW, Muris JW: Irritable bowel syndrome in primary care: The patients' and doctors' views on symptoms, aetiology and management. Can J Gastroenterol 2003;17 363-368.

19 Longstreth GF, Burchette RJ: Family practitioners' attitudes and knowledge about irritable bowel syndrome: Effect of a trial of physician education. Fam Pract 2003;20:670-674. 